\title{
Verbal Aggressiveness and Leadership Style of Sports Instructors and Their Relationship with Athletes’ Intrisic Motivation
}

\author{
Alexandra Bekiari \\ Department of Physical Education and Sports Science, University of Thessaly, Trikala, Greece \\ Email: sandrab@pe.uth.gr
}

Received September $16^{\text {th }}, 2013$; revised October $16^{\text {th }}, 2013$; accepted October $26^{\text {th }}, 2013$

\begin{abstract}
Copyright (C 2014 Alexandra Bekiari. This is an open access article distributed under the Creative Commons Attribution License, which permits unrestricted use, distribution, and reproduction in any medium, provided the original work is properly cited. In accordance of the Creative Commons Attribution License all Copyrights (C) 2014 are reserved for SCIRP and the owner of the intellectual property Alexandra Bekiari. All Copyright (C) 2014 are guarded by law and by SCIRP as a guardian.
\end{abstract}

\begin{abstract}
The purpose of the study was to examine intrinsic motivation of athletes and its relation with instructors' verbal aggressiveness and leadership style. The sample of the study consisted of 168 athletes (95 boys and 73 girls), 15 - 19 years old $(\mathrm{M}=16.5, \mathrm{SD}=0.5)$, participating in different individual and team sports (basketball, volleyball, football, long jump, pole vault, $200 \mathrm{~m}$ ). Every participant completed three questionnaires, the Verbal Aggressiveness Questionnaire, the Intrinsic Motivation Inventory, and the Leadership Scale for Sports. The results revealed differences existing among variables of the instruments in terms of sex and type of sport (individual or team sport and contact or non contact sport). Pearson correlation revealed a significant positive relationship of coaches' verbal aggressiveness with anxiety, autocratic style, and a negative significant relationship concerning coaches' verbal aggression with enjoyment, ability, effort, and democratic style. Findings and implications for instructors' type of communication were discussed and future research suggestions were included.
\end{abstract}

Keywords: Athletes; Intrinsic Motivation; Coaches; Verbal Aggressiveness; Leadership Style

\section{Introduction}

\section{Intrinsic Motivation}

The concept of motivation is generally referred to the way with which each person prompts himself to achieve his objectives. Related research in this field found that individual's achievement targets are determined by whatever the individual considers important and desirable (Dweck \& Leggett, 1988; Nicholls, 1989, 1992; Duda, 1992, 1993). A theoretical frame that is often used and more for the study of motivation in the field of physical education is the theory of self-determination (Deci \& Ryan, 1985; Ryan \& Deci, 2000). Intrinsic motivation appears to have the higher level of motivation which derives from self-determination. As intrinsic motivation is defined the participation in activities that people perceived interesting and pleasure (Vallerand, Deshaies, Cuerrier, Pelletier, \& Mongeau, 1992). According to Vallerand and Rousseau (2001) there are three main types of intrinsic motivation: intrinsic motivation "to know", intrinsic motivation "to accomplish", and intrinsic motivation "to experience" stimulation. Ryan and Deci (2000) suggested that intrinsic motivation is important for self-determined and autonomy behaviour.

Moreover, it has been shown to relate positively with competence and satisfaction. A study conducted by Jowett and Ntoumanis, (2001) revealed the existence of a reciprocal relationship and interaction between coaches and athletes. In sports field Mageau and Vallerand (2003) suggested that intrinsic motivation positively related with autonomy-supportive climate provided by coach. Also, Amorose and Horn (2000) suggested that a low in autocratic style and high in democratic style coach leads their athletes to a high level of intrinsic motivation. Furthermore, the coach who used mainly the democratic style and rarely the autocratic style, it is likely to advance an autonomy climate which, in turn, would have a positive impact on intrinsic motivation. Results of another study (Hollembeak \& Amorose, 2005) indicated the existence of a significant positive relationship between intrinsic motivation and athlete's perceived competence, autonomy and relatedness. Also, aforementioned researches found that all coaching behaviours (training and instruction, positive feedback, social support, and democratic behaviour) positively associated with intrinsic motivation except of autocratic behaviour which related negatively. Furthermore, the above study indicated that individual sport athletes perceived that their coaches were more likely to use democratic style and reported higher level of intrinsic motivation, autonomy and relatedness compare to team sport athletes. On the contrary team sports athletes perceived that their coaches tend to involve more in autocratic behaviour and training instruction than individual sport athletes.

A clear comprehension of motivation, however, requires that the target of behavior should be recognized. The objectives of individuals seem to determine the type of motivation they experience, which in turn is related to certain behaviors. Frederick and Ryan (1995) support the notion that the participation in activities for a long period of time is more likely to happen when individuals are internally rather than externally motivated. 
Moreover, it has been found that internal motivation predicts the intention of students to maintain their attendance in physical education activities (Goudas, Biddle, \& Underwood, 1995). On the other hand, detachment from sports appears to be connected with decreased internal motivation (Pelletier, Fortier, Vallerand, Tuson, Briere, \& Blais, 1995).

\section{Verbal Aggressiveness}

In all types of relationships, research consistently shows that verbal aggression leads to negative outcomes (Infante, Myers, \& Buerkel, 1994; Martin \& Anderson, 1995; Infante \& Rancer, 1996; Myers \& Rocca, 2000b) leading to learned helplessness (Infante, 1995; Infante \& Rancer, 1996). Studies conducted in the academic domain showed that verbal aggression is a demotivating force in the classroom (Gorham \& Christophel, 1992) that is negatively related to social attraction and liking for the source of aggressiveness (Martin, Heizel, \& Valencic, 1999), student perceptions of the teacher (Martin, Weber, \& Burant, 1997), perceptions of immediacy and interpersonal attraction (Rocca \& McCroskey, 1999), students' feelings of learner empowerment (Burant, 1999), students' attendance (Rocca, 2004) and participation (Rocca, 2000), and students affect toward the teacher, the course content, and the recommended course behaviors (Myers \& Knox, 1999; Wrench \& Richmond, 2004). A negative relationship between advisor verbal aggressiveness and advisee affect found Wrench and Punyanunt-Carter (2005) and also, suggested that advisor verbal aggressiveness negatively related to advisee perceived credibility. Schrodt (2003) found that students' perception of their instructor verbal aggressiveness negatively correlated with their perceptions of understanding, instructor credibility, and evaluations. Myers, Edwards, Wahl, and Martin (2007) revealed the negative impact of instructor verbal aggressiveness on their students' classroom involvement and motives to communicate with him. Research conducted by Myers and Rocca (2000a) revealed that students' state motivation negatively correlated with perceived use of seven verbally aggressive messages (attacks on competence, character, or background, malediction, ridicule, threats, and nonverbal symbols). Only three verbally messages (attacks on physical appearance, teasing, or swearing) were not related to state motivation. Myers and Rocca (2001) found that verbal aggressiveness was negatively related to students' perception of classroom climate and state motivation.

However, to the best of my knowledge, there is little research exploring PE teachers' verbal aggression in PE classes. In particular, research demonstrated that students who perceived their $\mathrm{PE}$ instructors as verbally aggressive reported greater learning loss in physical education classes (Bekiari, Kokaridas, \& Sakellariou, 2005). In addition, Bekiari (2012) found a negative relationship between PE teachers' perceived verbal aggressiveness and students' affective learning, and satisfaction in the field of physical education. Another study indicated that the antisocial fair play behaviors positively correlated with teachers' verbal aggression, while the prosocial fair play behaviors negatively correlated with PE teachers' verbal aggression (Hassandra, Bekiari, \& Sakellariou, 2007). Moreover, in physical education classes, it was revealed that there was a negative relationship between teachers' verbal aggression and lesson satisfaction, the motivation factors of enjoyment/interest, competence, and effort/importance, and the discipline factors of in- trinsic and caring reasons (Bekiari, Kokaridas, \& Sakellariou, 2006).

At the same time, few studies have probed into coaches' verbal aggressiveness. For example, Bekiari, Digelidis and Sakellariou (2006) found that athletes who took part in a noncontact sport viewed their coaches as less verbally aggressive compared to athletes participating in a high-contact sport. Additionally, Bekiari, Patsiaouras, Kokaridas, and Sakellariou (2006) showed that male volleyball players rated somatic anxiety higher and were more influenced by the verbal aggressiveness of their coaches than female volleyball players. Other studies mainly examined the relationship between athletes' aggressiveness and the type of sport (contact or non-contact) (Bredemeier, Weiss, \& Shields, 1986; Huang \& Cherek, 1999; Lemieux, McKelvie, \& Stout, 2002). More often than not, though the use of verbal aggression leads to negative results in most settings, it is quite acceptable in sports. Namely, it is likely that a verbally aggressive coach should lead their athletes to be motivated to perform better in order to achieve a champion's level of competition; however, verbal aggressiveness make athletes less willing to contact with their coach.

\section{Leadership Style}

As far as leadership is concerned, it is defined as the process of influencing the activities of an individual or a group in efforts toward goal achievement in a given situation (Hersey \& Blanchard, 1982). Based on situational leadership theory (Hersey \& Blanchard, 1969), Chelladurai and Saleh (1980) proposed Multidimensional Leadership Theory as an application to the sports field. Also, Multidimensional Leadership Theory proposes that leadership strategies in the context of sport consist of five dimensions: a) autocratic behaviour, b) democratic behaviour, c) social support, d) positive feedback, e) training and instruction. Turman (2001) examined athlete's (wrestlers) perception and preferences as well coaches' perceptions of leadership behaviours during a season. Results indicated that the success of their goals is a determinant factor on athlete's perceptions of their coaches' use of autocratic style. Successful teams' athletes perceived that their coaches utilize the same amount of autocratic style throughout the season. In contrast athletes of unsuccessful team perceived as inclined the use of their coaches' autocratic style during the season. Turman (2003) in another study suggested that both athletes' preferences and perception of coaches' autocratic behaviours were higher at the middle and at the end of the season. In addition Turman (2003) also found that experienced coaches perceived themselves as more autocratic at the end of the season than at the beginning. Conversely, inexperienced coaches perceived themselves as more autocratic at the end of the season than at the beginning or at the middle of the season. Riemer and Chelladurai (1995) examined the differences between offensives and defensives football players concerning their perceived and preferred leadership style and found that defensive players reported greater preferences and perceived greater amounts of democratic and autocratic behaviour than did offensive players.

Loughead and Hardy (2005) investigated athletes' perceptions of coaches and peers leaders, and found that coaches demonstrated greater amounts of autocratic behaviour comparing to peer leaders, whereas peer leaders exhibited greater amounts of democratic behaviours than coaches. Concerning, 
perceptions of coaches' leadership styles, male athletes reported higher levels of autocratic behaviour (Beam, Serwatka, \& Wilson, 2004; Chelladurai \& Saleh, 1978) in comparison with female athletes. In contrast, female athletes preferred more democratic leadership behaviour (Chelladurai \& Saleh, 1978) from their coaches. Amorose and Horn (2000) found that democratic style is more important to female athletes' intrinsic motivation compared to male.

Another line of research found that it is likely for autonomysupportive coaches to increase their students' motivation and satisfaction derived from the lesson and, finally, their intention to participate in physical activities during leisure time (Chatzisarantis \& Hagger, 2009).

What is more, the findings of a qualitative study revealed that activity instructors' positive leadership style increased female participants' self-efficacy, satisfaction, and intrinsic motivation rendering them more willing participants in similar physical activities (Lloyd \& Little, 2010).

\section{The Problem and the Aim of the Study}

According to the above, we can conclude that undoubtedly, verbal aggressiveness is negatively related to state motivation or act as a demotivating force in the educational domain. Unfortunately there does not exist any relatively study in the sports setting. A negative teacher trait such as verbal aggressiveness (Myers \& Knox, 1999; Roach, 1995) that undermine learning, are similar to autocratic coaching behaviours. Also according to Lewin and Gold (1999), aggression was much more common while autocratic leadership style was operating. In addition, autocratic style can lead to social problems within the classroom. While, in sport setting, Shields, Bredemeier, Gardner and Bostrom (1995) state that autocratic coaching style facilitates the acceptance of unsporting behaviour (cheating and aggressiveness) in a team. Their statement is based on the high correlation they found between the autocratic coaching leadership style and the shared rules (cheating and aggressiveness) accepted as valid by the team. Consequently, we can assume that autocratic leadership style it is likely to act as a demotivating force not only in the educational domain but and in the sport setting also. Studies suggested that coaches have an important influence in all aspects of athletes' preparations for competition and in determining athletes' success and development (DurandBush \& Salmela, 2002). Also, coaches are perceived to have a key point role in all aspects of athletes' career's, as well as in training and competition (Lyle, 1999).

Reviewing the literature, however, it seems that there is a lack of research exploring athletes' internal motivation with relation to verbal aggressiveness of coaches as perceived by athletes and coaches' leadership style (democratic or autocratic). This study attempted to examine intrinsic motivation of athletes and its relation with coaches' verbal aggressiveness and leadership style. More specifically, the main purpose of this study was to investigate the relation between intrinsic motivation of athletes and coaches' verbal aggressiveness and also, the relationship between verbal aggressiveness of coaches and their leadership style. The second purpose was to investigate if there were differences in verbal aggressiveness, intrinsic motivation, and leadership style, between the sexes and types of sports (individual or team sport and contact or non contact sport) that athletes participate?

\section{Method}

\section{Participants}

The sample of the study consisted of 168 Greek athletes (95 males and 73 females), 15 - 19 years old $(M=16.5$, $S D=0.5)$. All participants were members of individual $(\mathrm{N}=97)$ and team ( $\mathrm{N}=71$ ) sport clubs. More specifically, 43 runners, 32 shooters, 8 jumpers, 32 basketball players, 26 volleyball players and 27 football players. They participated voluntarily in the study, under the instruction of male coaches as extracurricular activities in athletic clubs located in a provincial city of Greece, Trikala. Researcher was available to provide explanation throughout the data collection process.

\section{Procedures}

Every participant completed three questionnaires, the Verbal Aggressiveness Questionnaire (Bekiari, Digelidis, Hatzigeorgiadis, \& Sakellariou, 2005), the Intrinsic Motivation Inventory (Ryan, 1982; McAuley, Duncan, \& Tammen, 1989), and the Leadership Scale for Sports (L.S.S., Chelladurai \& Saleh, 1980). All questionnaires were published in the English language and were translated into Greek with the use of back-translation procedure. The researchers gave verbal instructions prior to the completion of the questionnaires and they were present during the whole procedure to answer questions posed by the athletes. The participants were asked to respond to each statement of the questionnaires using a 5-point Likert Scale (anchored by strongly/totally disagree and strongly/totally agree).

\section{Measures}

Verbal Aggressiveness Scale. The Verbal Aggressiveness Questionnaire (Bekiari, Digelidis, Hatzigeorgiadis, \& Sakellariou, 2005) is designed to assess students' perceptions of physical education instructors' verbal aggressiveness. The questionnaire was structured according to the theoretical basis formulated by Infante and Wigley (1986) and comprised of 8 items describing verbal aggressiveness (e.g., "insults toward students", "negative judgments on students' ability”). Participants were asked to respond on a 5-point Likert-type scale from 1 to 5 , where 1 = strongly disagree, and $5=$ strongly agree.

Intrinsic Motivation Inventory. The Intrinsic Motivation Inventory (Ryan, 1982; McAuley, Duncan, \& Tammen, 1989), a 20-item version first used in Greek physical education settings (Goudas, Dermitzaki, \& Bagiatis, 2000) includes four subscales: enjoyment/interest, effort/importance, competence, and pressure/tension. Responses to the items were indicated on a 5point Likert-type scale, anchored by 1 = strongly disagree and 5 $=$ strongly agree.

Leadership Scale. The Leadership Scale for Sports (L.S.S.), (Chelladurai \& Saleh, 1980), a shorter version of the "Leadership Scale for Sports” (L.S.S.), (Chelladurai \& Saleh, 1980) was used in order to measure perceived coaches' leadership style. This short version consisted of 6 items describing autocratic leadership and 5 items describing democratic leadership teaching style, only two of the five dimensions were used. Responses were given on a 5-point Likert-type scale (1 = strongly disagree, 5 = strongly agree).

\section{Data Analysis}

Statistical analysis included the use of the statistical package 


\section{A. BEKIARI}

SPSS (11.0). Cronbach alpha Reliability analysis was used to examine the internal consistency of the factors of each questionnaire. Pearson correlation was used to determine the relationship between the factors of the questionnaires. A t-test analysis for independent samples was used to estimate possible differences existing in terms of sex and type of sport (individual or team sport and contact or non-contact sport). Statistical significance was set at $0.05(p<.05)$.

\section{Results}

Cronbach's Alpha reliability analysis of intrinsic motivation, verbal aggressiveness and leadership style.The factors of verbal aggressiveness $(\alpha=.93)$ showed a high degree of reliability for the questionnaire of Bekiari et al. (2005). The factors of enjoyment $(\alpha=.85)$, ability ( $\alpha=.90)$, effort $(\alpha=.67)$ and anxiety $(\alpha=.87)$ of the Intrinsic Motivation Inventory (Goudas, et al., 2000) showed a satisfactory or high level of reliability. The factors of democratic leadership style $(\alpha=.95)$ and autocratic $(\alpha=.92)$ of the questionnaire of Chelladurai and Saleh (1980) showed a high degree of reliability.

Correlation between intrinsic motivation, verbal aggressiveness and leadership style. Pearson correlation revealed a significant relationship existing among all factors. In particular, there was a significant positive relationship of coaches' verbal aggressiveness with anxiety $(r=.73)$ and autocratic style ( $\mathrm{r}$ $=.91$ ). A negative significant relationship concerning coaches' verbal aggression with enjoyment $(r=-.76)$, ability $(r=-.59)$, effort $(r=-.42)$, and democratic style $(r=-.92)$ was also noticed (Table 1).

Gender differences. Statistically significant differences were observed in coaches' verbal aggressiveness (t1.166 $=-4.82, p$ $<.05$ ), enjoyment ( $\mathrm{t} 1.166=4.38, p<.05)$, ability ( $\mathrm{t} 1.166=$ $3.35, p<.05)$, effort (t1.166 $=2.85, p<.05)$, anxiety (t1.166 $=$ $-3.54, p<.05)$, democratic style (t1.166 $=4.98, p<.05)$ and autocratic style (t1.166 $=-4.62, p<.05)$ between the two genders (Table 2).

Differences concerning kind of sports. Statistically significant differences were also observed in coaches' verbal aggressiveness (t1.166 $=-2.11, p<.05)$, democratic style $(\mathrm{t} 1.166=2.64$, $p<.05)$ and autocratic style (t1.166 $=-2.15, p<.05)$ between individual and team sports (Table 3 ). No differences were found regarding the other variables of the instruments.

Differences concerning sports' type. In terms of contact or non contact sports statistical analysis revealed significant differences in coaches' verbal aggressiveness (t1.166 $=-2.11, p$ $<.05$ ), anxiety (t1.166 $=-2.02, p<.05)$, democratic style $(\mathrm{t} 1.166=2.98, p<.05)$ and autocratic style $(\mathrm{t} 1.166=-2.89, p$ $<.05)$. No differences were noticed concerning the other variables of the instruments (Table 4).

Table 1.

Correlations among variables.

\begin{tabular}{|c|c|c|c|c|c|c|c|}
\hline & 1 & 2 & 3 & 4 & 5 & 6 & 7 \\
\hline 1. Verbal aggression & 1.00 & & & & & & \\
\hline 2. Enjoyment & $-.76^{* *}$ & 1.00 & & & & & \\
\hline 3. Ability & $-.59^{* *}$ & $.50^{* *}$ & 1.00 & & & & \\
\hline 4. Effort & $-.42^{* *}$ & $.63^{* *}$ & $.39^{* *}$ & 1.00 & & & \\
\hline 5. Anxiety & $.73^{* *}$ & $-.78^{* *}$ & $-.51^{* *}$ & $-.60^{* *}$ & 1.00 & & \\
\hline 6. Democratic style & $-.92^{* *}$ & $.72^{* *}$ & $.58^{* *}$ & $.43^{* *}$ & $-.72^{* *}$ & 1.00 & \\
\hline 7. Autocratic style & $.91^{* *}$ & $-.74^{* *}$ & $-.59^{* *}$ & $-.47^{* *}$ & $.78^{* *}$ & $-.93^{* *}$ & 1.00 \\
\hline
\end{tabular}

${ }^{* *} p<.001$.

Table 2.

Descriptive statistics and t-test results according to sex.

\begin{tabular}{|c|c|c|c|c|c|c|}
\hline \multirow{2}{*}{ Factors } & \multicolumn{2}{|c|}{ Boys } & \multicolumn{2}{|c|}{ Girls } & \multirow[t]{2}{*}{$\mathrm{t}$} & \multirow[t]{2}{*}{$p$} \\
\hline & M & SD & M & SD & & \\
\hline Verbal aggressiveness & 2.92 & 1.05 & 3.64 & .86 & -4.82 & .000 \\
\hline Enjoyment & 2.73 & .88 & 2.23 & .59 & 4.38 & .000 \\
\hline Ability & 2.98 & 1.00 & 2.52 & .76 & 3.35 & .001 \\
\hline Effort & 2.70 & .65 & 2.43 & .58 & 2.85 & .005 \\
\hline Anxiety & 2.93 & .94 & 3.40 & .76 & -3.54 & .001 \\
\hline Democratic style & 3.13 & 1.10 & 2.33 & .95 & 4.98 & .000 \\
\hline Autocratic style & 2.76 & 1.20 & 3.55 & .98 & -4.62 & .000 \\
\hline
\end{tabular}


Table 3.

Descriptive statistics and t-test results according to individual or team sports.

\begin{tabular}{|c|c|c|c|c|c|c|}
\hline \multirow{2}{*}{ Factors } & \multicolumn{2}{|c|}{ Individual Sport } & \multicolumn{2}{|c|}{ Team Sport } & \multirow[t]{2}{*}{$\mathrm{t}$} & \multirow[t]{2}{*}{$p$} \\
\hline & M & SD & M & SD & & \\
\hline Verbal aggressiveness & 3.10 & 1.05 & 3.44 & .98 & -2.11 & .036 \\
\hline Democratic style & 2.96 & 1.14 & 2.51 & 1.02 & 2.64 & .00 \\
\hline Autocratic style & 2.95 & 1.21 & 3.34 & 1.08 & -2.15 & .03 \\
\hline
\end{tabular}

Table 4.

Descriptive statistics and t-test results according to contact or non contact sport.

\begin{tabular}{|c|c|c|c|c|c|c|}
\hline \multirow{2}{*}{ Factors } & \multicolumn{2}{|c|}{ Non-Contact Sport } & \multicolumn{2}{|c|}{ Contact Sport } & \multirow[t]{2}{*}{$\mathrm{t}$} & \multirow[t]{2}{*}{$p$} \\
\hline & M & SD & M & SD & & \\
\hline Verbal aggressiveness & 2.95 & 1.32 & 3.62 & 1.32 & -3.23 & .00 \\
\hline Anxiety & 2.98 & .92 & 3.26 & .86 & -2.02 & .04 \\
\hline Democratic style & 3.07 & 1.14 & 2.56 & 1.04 & 2.98 & .00 \\
\hline Autocratic style & 2.81 & 1.25 & 3.34 & 1.06 & -2.89 & .00 \\
\hline
\end{tabular}

\section{Discussion}

The results of this study revealed that verbal aggressiveness is negatively associated with enjoyment, ability, effort of the athletes and the democratic style of the instructor. In other words, verbal aggressiveness once again appears to be a demotivating force in the sports setting and this is in agreement with the study of Gorham and Christophel (1992) which conducted in the educational field. As results showed, verbal aggressiveness leads to an increased anxiety and is strictly related to autocratic style of teaching. An anxious person who receives verbal aggressiveness by his instructor does not enjoy teaching (Myers, 2002; Myers \& Knox, 2000). As a result, athletes often exhibit a lack of desire to perform or make an effort in sports. On the other hand, democratic style of teaching leads to an increased enjoyment and effort of the athletes to express their ability (Schmuck \& Schmuck, 1968).

According to Infante (1989), educators tended to be less verbally aggressive toward girls. Boys are usually less obedient toward instructors, which in turn results to an increased verbal aggressiveness on behalf of the instructors in their attempt to impose discipline. Indeed, female athletes of this study seemed to perceive their instructors' behavior as more aggressive and less democratic compared to males. As a consequence, results revealed that girls' derived decreased enjoyment and tended to perform less and express their abilities in comparison with boys. In addition, the findings of a number studies (Amorose \& Horn, 2000; Chelladurai \& Saleh, 1978; Chelladurai, 1993; Eccles \& Harold, 1991; Martin, Jackson, Richardson, \& Weiller, 1999) found that female athletes exhibited higher preferences for democratic coaching style than did male athletes. At the same time, Beam, Serwatka, and Wilson (2004) found that significant differences in gender, as male student-athletes showed significantly greater preferences for autocratic and social support behaviour than their female counterparts. Thus, it is rational to assume that the female athletes of the present study derived less enjoyment and more anxiety under the autocratic leadership style of their coaches when compared to male athletes.
Athletes participating in team sports seem to perceive instructors' behavior as more verbally aggressive and more related to autocratic style of teaching as compared to individual sports' athletes. It seems that coaching a group of athletes in a team sport is a more demanding task that obliges coaches to adopt a more autocratic style of teaching in order to achieve his goals. On the other hand, coaching athletes of individual sports demands a personal relation with their athletes and it is likely to constitute a deterrent factor to exhibit a verbally aggressive behavior.

Autocratic style of teaching was found to be adopted more by contact sport coaches. In particular, basketball and football coaches of this study were perceived as more verbally aggressive and autocratic by their athletes leading to an increased anxiety, as compared to non-contact (volleyball, long jump, pole vault, $200 \mathrm{~m}$ ) sports' coaches. Contact sports increase competitiveness and tension among athletes which in turn requires coaches to adopt a more "aggressive" profile to counterbalance the demands of the game (Bekiari, Digelidis, \& Sakellariou, 2006). It appears that contact type sport athletes still perceived as more verbally aggressive their coaches than non contact type sport athletes. It is rational to be assumed that athletes participating in contact sports due to the nature of the sports (physical contact, prolonged tension and effort for win) inherently emit more frequently aggressive behaviors than non-contact sports.

The findings of this investigation suggest that if the goal of coaching is to increase enjoyment, ability, and effort of athletes to pursue their goals then coaches must consider the types of communicative messages that students are motivated by and respond to positively. The goal of coaches who are interested in creating an environment, in which intrinsic motivation can occur, is to create opportunities for student control in the classroom or at least to feel that participate in the receiving decisions. Athletes who take control of their training experience will then derive personal rewards from their own successful completion of their tasks.

Future studies should examine the relationship of verbal aggressiveness, leadership style and intrinsic motivation in other 
sports using larger samples in order to provide more precise and more reliable measures. Also in a future study we should examine some important coaches' descriptive characteristics such as age, sex, family status, social and economical status in order to found if and how determinant these factors influenced on coaches' verbal aggressiveness and leadership style. Additionally, a future research with personal coaches' interviews and questionnaires for athletes at the same time, it would be interesting to be conducted in order to compare coaches' self-reported verbal aggressiveness and athletes perceptions of their coaches' verbal aggressiveness, to determine if these types of communicative behaviours effect athletes' intrinsic motivation.

\section{REFERENCES}

Amorose, A. J., \& Horn, T. S. (2000). Intrinsic motivation: Relationships with collegiate athletes' gender, scholarship status, and perceptions of their coaches' behavior. Journal of Sport and Exercise Psychology, 22, 63-84.

Beam, J. W., Serwatka, T. S., \& Wilson, W. J. (2004). Preferred leadership of NCAA Division I and II intercollegiate student-athletes. Journal of Sport Behavior, 27, 3-17.

Bekiari, A. (2012). Perceptions of instructors' verbal aggressiveness and physical education students' affective learning. Perceptual and Motor Skills, 115, 325-335. http://dx.doi.org/10.2466/06.11.16.PMS.115.4.325-335

Bekiari, A., Digelidis, N., Hatzigeorgiadis, A., \& Sakellariou, K. (2005). Development of a scale to assess verbal aggressiveness in the physical education context. Italian Journal of Sport Sciences, 13, 24-27.

Bekiari, A., Digelidis, N., \& Sakellariou, K. (2006). Perceived verbal aggressiveness of coaches in volleyball and basketball: A preliminary study. Psychological Reports, 103, 526-530.

Bekiari, A., Kokaridas, D., \& Sakellariou, K. (2005). Verbal aggressiveness of physical education teachers and students' self-reports of behaviour. Phychological Reports, 96, 493-498. http://dx.doi.org/10.2466/pr0.96.2.493-498

Bekiari, A., Kokaridas, D., \& Sakellariou, K. (2006). Associations of students' self-reports of their teacher's verbal aggression, intrinsic motivation, and perceptions of reasons for discipline in Greek physical education classes. Phychological Reports, 98, 451-461. http://dx.doi.org/10.2466/pr0.98.2.451-461

Bekiari, A., Patsiaouras, A., Kokaridas, D., \& Sakellariou, K. (2006). The relationship between verbal aggressiveness and state anxiety in volleyball. Perceptual and Motor Skills, 99, 630-634.

Bredemeier, B., Weiss, M., \& Shields, D. (1986). The relationship of sport involvement with children's moral reasoning and aggression tendencies. Journal of Sport Psychology, 8, 304-318.

Burant, P. A. (1999). Students' perceptions of teachers' communication and it's effects on students' learning. Unpublished Dissertation, Morgantown, WV: College of Human Resources and Education at West Virginia University.

Chatzisarantis, N., \& Hagger, M. (2009). Effects of an intervention based on self-determination theory on self-reported leisure-time physical activity participation. Psychology \& Health, 24, 29-48. http://dx.doi.org/10.1080/08870440701809533

Chelladurai, P., \& Saleh, S. D. (1978). Preferred leadership in sports. Canadian Journal of Applied Sport Sciences, 3, 85-92.

Chelladurai, P., \& Saleh, S. D. (1980). Dimensions of leader behaviour in sports: Development of a leadership scale. Journal of Sport Psychology, 2, 34-45.

Chelladurai, P (1993). Leadership. In R. N. Singer, M. Murphey, \& L. K. Tennant (Eds.), Handbook of research on sport psychology (pp. 647-671). New York: Macmillan.

Deci, E. L., \& Ryan, R. M. (1985). Intrinsic motivation and selfdetermination in human behavior. New York: Plenum. http://dx.doi.org/10.1007/978-1-4899-2271-7

Duda, J. L. (1992). Motivation in sport settings: A goal perspective approach. In G. Roberts (Ed.), Motivation in sport and exercise (pp.
57-91). Champaign, IL: Human Kinetics Publishers.

Duda, J. L. (1993). Goals: A social-cognitive approach to the study of achievement motivation in sport. In R. N. Singer (Ed.), Handbook of research on sport psychology (pp. 421-436). New York: MacMillan.

Durand-Bush, N., \& Salmela, J. H. (2002). The development and maintenance of expert athletic performance: Perceptions of world and Olympic champions. Journal of Applied Sport Psychology, 14, 154-171. http://dx.doi.org/10.1080/10413200290103473

Dweck, C. S., \& Leggett, E. L. (1988). A social-cognitive approach to motivation and personality. Psychological Review, 95, 256-273. http://dx.doi.org/10.1037/0033-295X.95.2.256

Eccles, J. S., \& Harold, R. D. (1991). Gender differences in sport involvement: Applying the Eccles’ Expectancy-Value Model. Journal of Applied Sport Psychology, 3, 7-35. http://dx.doi.org/10.1080/10413209108406432

Frederick, C. M., \& Ryan, R. M. (1995). Self-determination in sport: A review using cognitive evaluation theory. International Journal of Sport Psychology, 26, 5-23.

Gorham, J., \& Christophel, D. M. (1992). Students' perceptions of teacher behaviours as motivating and de-motivating factors in college classes. Communication Quarterly, 40, 239-252. http://dx.doi.org/10.1080/01463379209369839

Goudas, M., Biddle, S., \& Underwood, M. (1995). A prospective study of the relationship between motivational orientations and perceived competence with intrinsic motivation and achievement in a teacher education course. Educational Psychology, 15, 89-96. http://dx.doi.org/10.1080/0144341950150108

Goudas, M., Dermitzaki, I., \& Bagiatis, K. (2000). Predictors of students' intrinsic motivation in school physical education. European Journal of Psychology of Education, 15, 271-280. http://dx.doi.org/10.1007/BF03173179

Hassandra, M., Bekiari, A., \& Sakellariou, K. (2007). Physical education teacher's verbal aggression and student's fair play behaviors. The Physical Educator, 64, 94-101.

Hersey, P., \& Blanchard, K. (1969). Life cycle theory of leadership. Training and Development Journal, 23, 26-35.

Hersey, P., \& Blanchard, K. (1982). Management and organizational behavior: Utilizing human resources (4th ed.). Englewood Cliffs, NJ: Prentice-Hall.

Hollembeak, J., \& Amorose, A. J. (2005). Perceived coaching behaviors and college athletes' intrinsic motivation: A test of self-determination theory. Journal of Applied Sport Psychology, 17, 20-36. http://dx.doi.org/10.1080/10413200590907540

Huang, D., \& Cherek, D. (1999). Laboratory measurement of aggression in high school age athletes: Provocation in a non-sporting. Psychological Reports, 85, 1251-1263.

http://dx.doi.org/10.2466/pr0.1999.85.3f.1251

Infante, D. A. (1989). Response to high argumentatives: Message and sex differences. Southern Communication Journal, 54, 159-170. http://dx.doi.org/10.1080/10417948909372753

Infante, D. A. (1995). Teaching students to understand and control verbal aggression. Communication Education, 44, 51-63. http://dx.doi.org/10.1080/03634529509378997

Infante, D. A., \& Rancer, A. S. (1996). Argumentativeness and verbal aggressiveness: A review of recent theory and research. Communication Yearbook, 19, 319-351.

Infante, D. A., \& Wigley, C. J. (1986). Verbal aggressiveness: An interpersonal model and measure. Communication Monographs, 53, 6169. http://dx.doi.org/10.1080/03637758609376126

Infante, D. A., Myers, S. A., \& Buerkel, R. A. (1994). Argument and verbal aggression in constructive and destructive family and organizational disagreements. Western Journal of Communication, 58, 7384. http://dx.doi.org/10.1080/10570319409374488

Jowett, S., \& Ntoumanis, N. (2001). The Coach-Athlete Relationship Questionnaire(CART-Q): Development and Initial Validation. Unpublished manuscript, Stoke-on-Trent: Staffordshire University.

Lemieux, P., McKelvie, S., \& Stout, D. (2002). Self-reported hostile aggression in contact athletes, no contact athletes and non-athletes. Online Journal of Sport Psychology, 4.

Lewin, K., \& Gold, M. (1999). Complete social scientist: A Kurt Lewin 
reader. In K. Lewin, \& M. Gold (Eds.), American psychological association (pp. 267-250). Washington, DC: American Psychological Association. http://dx.doi.org/10.1037/10319-000

Lloyd, K., \& Little, D. (2010). Keeping women active: An examination of the impacts of self-efficacy, intrinsic motivation, and leadership on women's persistence in physical activity. Women \& Health, 50, 652-669. http://dx.doi.org/10.1080/03630242.2010.520250

Loughead, T. M., \& Hardy, J. (2005). An examination of coach and peer leader behaviors in sport. Psychology of Sport and Exercise, 6, 303-312. http://dx.doi.org/10.1016/j.psychsport.2004.02.001

Lyle, J. (1999). The coaching process: An overview. In N. Cross, \& Lyle, J. (Eds.), The coaching process: Principles and practice for sports (pp. 25-46). Oxford: Butterworth-Heinman.

Mageau, G. A., \& Vallerand, R. J. (2003). The coach-athlete relationship: A motivational model. Journal of Sports Sciences, 21, 883-904. http://dx.doi.org/10.1080/0264041031000140374

Martin, M. M., \& Anderson, C. M. (1995). Roommate similarity: Are roommates who are similar in their communication traits more satisfied? Communication Research Reports, 12, 46-52. http://dx.doi.org/10.1080/08824099509362038

Martin, M. M., Heizel, A. D., \& Valencic, K. M. (1999). Verbal aggression in computer-mediated decision-making. The Annual Meeting of the National Communication Association, Chicago, 12-15 November 1999, 21p.

Martin, M. M., Weber, K., \& Burant, P. A. (1997). Students' perceptions of a teacher's use of slang and verbal aggressiveness in a lecture: An experiment. The Annual Meeting of the Eastern Communication Association, Baltimore, 10-13 April 1997, 24p.

Martin, S., Jackson, A., Richardson, P., \& Weiller, K. (1999). Coaching preferences of adolescent youths and their parents. Journal of Applied Sport Psychology, 11, 247-262. http://dx.doi.org/10.1080/10413209908404203

McAuley, E, Duncan, T., \& Tammen, V. V. (1989). Psychometric properties of the intrinsic motivation inventory in a competitive sport setting: A confirmatory factor analysis. Research Quarterly for Exercise and Sport, 60, 48-58.

http://dx.doi.org/10.1080/02701367.1989.10607413

Myers, S. A. (2002). Perceived aggressive instructor communication and student state motivation, learning and satisfaction. Communication Reports, 15, 113-121.

http://dx.doi.org/10.1080/08934210209367758

Myers, S. A., \& Rocca, K. A. (2000a). Students' state motivation and instructors' use of verbally aggressive messages. Psychological Reports, 87, 291-294. http://dx.doi.org/10.2466/pr0.2000.87.1.291

Myers, S. A., \& Rocca, K. A. (2000b). The relationship between perceived instructor communicator style, argumentativeness, and verbal aggressiveness. Communication Research Reports, 17, 1-12. http://dx.doi.org/10.1080/08824090009388745

Myers, S. A., \& Rocca, K. A. (2001). Perceived instructor Argumentativeness and verbal aggressiveness in the college classroom: Effects on student perceptions of climate, apprehension, state motivation. Western Journal of Communication, 65, 113-137. http://dx.doi.org/10.1080/10570310109374696

Myers, S. A., \& Knox, R. L. (1999). Verbal aggression in the college classroom: Perceived instructor use and student affective learning. Communication Quarterly, 47, 33-45. http://dx.doi.org/10.1080/01463379909370122

Myers, S. A., \& Knox, R. L. (2000). Perceived instructor argumentativeness and verbal aggressiveness and student outcomes. Сотmunication Research Reports, 17, 299-309. http://dx.doi.org/10.1080/08824090009388777

Myers, S. A., Edwards, C., Wahl, S. T., \& Martin, M. M. (2007). The relationship between perceived instructor aggressive communication and college student involvement. Communication Education, 56, 495508. http://dx.doi.org/10.1080/03634520701466398

Nicholls, J. G. (1989). The competitive ethos and democratic education. Cambridge, MA: Harvard University Press.

Nicholls, J. G. (1992). The general and the specific in the development and the expression of achievement motivation. In G. C. Roberts (Ed.),
Motivation in sport and exercise (pp. 31-56). Champaign, IL: Human Kinetics.

Pelletier, L. G., Fortier, M. S., Vallerand, R. J., Tuson, K. M., Briere, N. M., \& Blais, M. R. (1995). Toward a new measure of intrinsic motivation, extrinsic motivation, and amotivation in sports: The sport motivation scale (SMS). Journal of Sport and Exercise Psychology, 17, 35-53.

Reynolds, R., \& Allen, W. (2003). The effects of coach communicative aggression on athlete learning and motivation. Washington, DC: International Communication Association.

Riemer, H. A., \& Chelladurai, P. (1995). Leadership and satisfaction in athletics. Journal of Sport and Exercise Psychology, 17, 276-293.

Roach, K. D. (1995). Teaching assistant argumentativeness: Effects of affective learning and student perceptions of power use. Communication Education, 44, 15-29. http://dx.doi.org/10.1080/03634529509378994

Rocca, K. A. (2000). Attendance and participation in the college classroom: The role of the instructor. Unpublished Dissertation, Morgantown, WV: The College of Human Resources and Education at West Virginia University.

Rocca, K. A. (2004). College student attendance: Impact of instructor immediacy and verbal aggression. Communication Education, 53, 185195. http://dx.doi.org/10.1080/03634520410001682447

Rocca, K. A., \& McCroskey, J. C. (1999). The interrelationship of student ratings of instructors' immediacy, verbal aggressiveness, homophily, and interpersonal attraction. Communication Education, 48, 308-316. http://dx.doi.org/10.1080/03634529909379181

Ryan, R. M., \& Deci, E. L. (2000). Self-determination theory and the facilitation of intrinsic motivation, social development, and well-being. American Psychologist, 55, 68-78.

http://dx.doi.org/10.1037/0003-066X.55.1.68

Ryan, R. M. (1982). Control and information in the intrapersonal sphere: An extension of cognitive evaluation theory. Journal of Personality and Social Psychology, 43, 450-461.

http://dx.doi.org/10.1037//0022-3514.43.3.450

Schmuck, R. A., \& Schmuck, P. A. (1968). Helping teachers improve classroom group processes. The Journal of Applied Behavioral Science, 4, 401-435. http://dx.doi.org/10.1177/002188636800400402

Schrodt, P. (2003). Students' appraisals of instructors as a function of students' perceptions of instructors' aggressive communication. Communication Education, 52, 106-121. http://dx.doi.org/10.1080/03634520302468

Shields, D. L., Bredemeier, B. L., Gardner, D. E., \& Bostrom, A. (1995). Leadership, cohesion, and team norms regarding cheating and aggression. Sociology of Sport Journal, 12, 324-337.

Turman, P. D. (2001). Situational coaching styles: The impact of success and athlete maturity level on coaches' leadership styles over time. Small Group Research, 32, 576-594. http://dx.doi.org/10.1177/104649640103200504

Turman, P. D. (2003). Athletic coaching from an instructional communication perspective: The influence of coach experience on high school wrestlers' preferences and perceptions of coaching behaviors across a season. Communication Education, 52, 73-86. http://dx.doi.org/10.1080/03634520302465

Vallerand, R. J., Deshaies, P., Cuerrier, J., Pelletier, L. G., \& Mongeau, C. (1992). Ajzen and Fishbein's theory of reasoned action as applied to moral behavior: A confirmatory analysis. Journal of Personality and Social Psychology, 62, 98-109. http://dx.doi.org/10.1037/0022-3514.62.1.98

Vallerand, R. J., \& Rousseau, F. L. (2001). Intrinsic and extrinsic motivation in sport and exercise: A review using the hierarchical model of intrinsic and extrinsic motivation. In R. N. Singer, H. A. Hausenblas, \& C. M. Janelle (Eds.), Handbook of sport psychology (2nd ed., pp. 389-416). New York: Wiley.

Wrench, J. S., \& Richmond, V. P. (2004). Understanding the psychometric properties of the Humor Assessment instrument through an analysis of the relationships between teacher humor assessment and instructional communication variables in the college classroom. Communication Research Reports, 21, 92-103. 


\section{A. BEKIARI}

http://dx.doi.org/10.1080/08824090409359971

Wrench, J., \& Punyanunt-Carter, N. M. (2005). Advisor-advisee communication two: The influence of verbal aggression and humor as- sessment on advisee perceptions of advisor credibility and affective learning. Communication Research Reports, 22, 303-313. http://dx.doi.org/10.1080/000368105000317599 